Article

\title{
Simulation/Experiment Confrontation, an Efficient Approach for Sensitive SAW Sensors Design
}

\author{
Bilel Achour ${ }^{1}\left(\mathbb{D}\right.$, Ghada Attia $^{2}$, Chouki Zerrouki $^{2, *}{ }^{(}$, Najla Fourati $^{2}\left(\mathbb{D}\right.$, Kosai Raoof $^{1}{ }^{1}$ and \\ Nourdin Yaakoubi ${ }^{1, *}$ \\ 1 LAUM, UMR CNRS 6613, Le Mans Université, Avenue Olivier Messiaen, CEDEX 9, 72085 Le Mans, France; \\ bilel.achour@univ-lemans.fr (B.A.); kosai.raoof@univ-lemans.fr (K.R.) \\ 2 Cnam, SATIE, UMR CNRS 8029, 292 Rue Saint Martin, 75003 Paris, France; ghada.attia@lecnam.net (G.A.); \\ fourati@cnam.fr (N.F.) \\ * Correspondence: zerrouki@cnam.fr (C.Z.); nourdin.yaakoubi@univ-lemans.fr (N.Y.)
}

Received: 3 July 2020; Accepted: 31 August 2020; Published: 3 September 2020

\begin{abstract}
Sensitivity is one of the most important parameters to put in the foreground in all sensing applications. Its increase is therefore an ongoing challenge, particularly for surface acoustic wave (SAW) sensors. Herein, finite element method (FEM) simulation using COMSOL Multiphysics software is first used to simulate the physical and electrical properties of SAW delay line. Results indicate that $2 \mathrm{D}$ configuration permits to accurately obtain all pertinent parameters, as in $3 \mathrm{D}$ simulation, with very substantial time saving. A good agreement between calculation and experiment, in terms of transfer functions (S21 spectra), was also shown to evaluate the dependence of the SAW sensors sensitivity on the operating frequency; 2D simulations have been conducted on $104 \mathrm{MHz}$ and $208 \mathrm{MHz}$ delay lines, coated with a polyisobutylene (PIB) as sensitive layer to dichloromethane (DCM). A fourfold increase in sensitivity was obtained by doubling frequency. Both sensors were then realized and tested as chem-sensors to detect zinc ions in liquid media. 9-\{[4-(\{[4-(9anthrylmethoxy)phenyl]sulfanyl $\}$ methyl)]methyl] anthracene (TDP-AN) was selected as the sensing layer. Results show a comparable response curves for both designed sensors, in terms of limit of detection and dissociation constants $\mathrm{K}_{\mathrm{d}}$ values. On the other hand, experimental sensitivity values were of the order of $[7.0 \pm 2.8] \times 10^{8}\left[{ }^{\circ} / \mathrm{M}\right]$ and $[16.0 \pm 7.6] \times 10^{8}\left[{ }^{\circ} / \mathrm{M}\right]$ for $104 \mathrm{MHz}$ and $208 \mathrm{MHz}$ sensors, respectively, confirming that the sensitivity increases with frequency.
\end{abstract}

Keywords: finite element method (FEM) simulation; polyisobutylene (PIB); dichloromethane (DCM); anthracene; zinc ions; surface acoustic wave (SAW) sensors; dissociation constants

\section{Introduction}

Surface acoustic wave (SAW) devices are investigated in a large variety of applications including signal processing [1], mobile and wireless communication [2,3], modulators [4] and RF filters [5]. In the last decades, they have been more and more used as chemical and biological sensors due to their fast response [6], low cost [7], high sensitivity [8-13], low limit of detection [14,15] and real-time monitoring [16]. To design and optimize SAW sensors with time and money saving, several simulation methods were developed: delta function model [17], equivalent circuit model [18], P-matrix model [19], coupled mode theory [20], and CST (Computer Simulation Technology) software [21]. However, these methods are very complex and are mainly used in telecommunication applications such as filters and resonators. To overcome these limitations, Finite Element Method (FEM) simulation was investigated and has proven to be the most suitable method for metrological characterization of SAW devices prior to their fabrication in a clean room [22-26]. 
Sensitivity is one of the most important characteristic parameters of SAW chemical and biological sensors. Several theoretical research and simulations have therefore been conducted to improve sensors sensitivity. Abdoallahi et al. have carried out a 3D-FEM modelling to evaluate SAW devices mass sensitivity by calculating wave propagation speeds and the further energy distributions [27]. Zhao et al. investigated FEM modeling to analyze the polymer coating effects on the surface acoustic waves propagation in the absence and presence of vapor [28]. Richardson et al. have used 3D-FEM simulation to compare insertion loss and mass sensitivity of SAW sensors having microcavities filled with $\mathrm{ZnO}$ and nanocrystalline diamond (NCD) [29]. In a recent study, Abraham et al., achieved a significative improvement in sensitivity by functionalizing the SAW's sensing layer with $\mathrm{ZnO}-\mathrm{CuO}$ nanocomposites in MOX-CNT nanocomposite [30]. In the present work, we first used MATLAB to rapidly simulate the behavior of a delay line. Among the different models that can be implemented for this kind of system, crossed-field equivalent circuit model, coupling of modes model, impulse response model, we opted for the impulse response one [31]. FEM simulation, using COMSOL Multiphysics software, was then used as it allows to consider material density, particle displacement, and electric potential during the propagation of surface acoustic waves on the surface of a given piezoelectric material. Simulations started first on an existing SAW sensor operating at $104 \mathrm{MHz}$, by investigating different configurations. Only the one which was in perfect agreement with the experimental results was considered. This optimization phase has permitted to validate the accuracy of the simulations before their subsequent use to estimate the frequency responses of newly designed structures. To simulate the increase in sensitivity with the operating frequency, a polyisobutylene (PIB) layer, sensitive to dichloromethane (DCM) gas, was deposited on the SAWs sensing area. Based on the computational results, a new optimized structure was designed and tested for zinc ions detection. The choice of these ions is related to their presence in Sarthe River Basin of "Le Mans" region [32]. Several receptors have been investigated for zinc ions detection, mainly ion imprinted polymers [33-35], DNA [36], aptamers [37], self-assembled monolayers (SAM) [38,39], enzymes [40,41], and molecular cages [42-45]. Herein, we have chosen to functionalize the sensitive zone of the $104 \mathrm{MHz}$ and $208 \mathrm{MHz} \mathrm{SAW}$ sensor with 9-\{[4-(\{[4-(9 anthrylmethoxy) phenyl]sulfanyl $\}$ methyl)]methyl] anthracene (TDP-AN). This molecule was chosen among other ones due to its easiness to be synthetized and its capacity to bind to gold surfaces through the S-Au bond. Results were compared in terms of limit of detection (L.O.D), sensitivity, and dissociation constant $\left(\mathrm{K}_{\mathrm{d}}\right)$, which is related to the degree of the affinity between the analyte and the investigated sensing layer.

\section{Materials and Methods}

\subsection{Chemicals}

Sulfuric acid $\left(\mathrm{H}_{2} \mathrm{SO}_{4}, 98 \%\right)$, hydrogen peroxide $\left(\mathrm{H}_{2} \mathrm{O}_{2}, 30 \%\right)$, chloroform $\left(\mathrm{CHCl}_{3}\right)$, and zinc (II) chloride $\left(\mathrm{ZnCl}_{2}\right)$ were purchased from Sigma-Aldrich (St. Louis, $\left.\mathrm{MO}, \mathrm{USA}\right)$.

9-\{[4-(\{[4-(9 anthrylmethoxy) phenyl]sulfanyl $\}$ methyl $)]$ methyl] anthracene (TDP-AN), whose chemical structure is presented in Scheme 1, was synthetized via the Williamson reaction between 9-chloromethyl anthracene $(\mathrm{AnCl})$ and 4,4'-thiodiphenol.

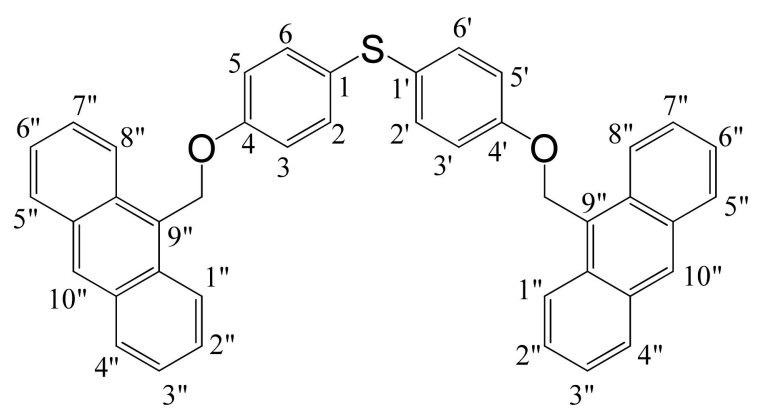

Scheme 1. Chemical structure of TDP-AN. 


\subsection{Gravimetric Measurements}

The designed 104 and $208 \mathrm{MHz}$ SAW sensors were fabricated on 36 YX-LiTaO 3 piezoelectric substrate. Their sensitive area and interdigital transducer electrodes (IDTs) were metallized with $20 \mathrm{~nm} / 80 \mathrm{~nm} \mathrm{Cr} / \mathrm{Au}$ layers. The $36 \mathrm{YX}$-cut allows mainly to generate two horizontal transverse waves on the surface of the LiTaO3 substrate: surface skimming bulk waves (SSBW) and leaky-SAW. These waves can however coexist with fast shear bulk acoustic waves and quasi-longitudinal bulk acoustic waves. However, and as the SAW sensing area was metallized with 20/80 nm $\mathrm{Cr} / \mathrm{Au}$ thin layers, LSAW propagation was favored compared to SSBW. Besides, bulk acoustic waves (BAWs) are equally generated with a lesser magnitude and propagate in the material under certain inclination. Their detection is thus possible after backscattering.

To obtain an operating frequency of about 104 and $208 \mathrm{MHz}$ sensors, the IDTs were photolithographically patterned with a periodicity of 40 and $20 \mu \mathrm{m}$ respectively (See Supplementary Materials Figure S1). The measurement setup consists of (i) a SAW sensor (See Supplementary Materials Figure S2); (ii) a printed circuit board to ensure electrical contacts (See Supplementary Materials Figure S3); (iii) a Kalrez ${ }^{\circledR}$ flow cell deposited on the sensing area; (iv) a PMMA cover including inlets and outlets pipes were connected to a Gilson ${ }^{\circledR} 3$ peristaltic pump to ensure continuous fluids flow of order of $190 \mu \mathrm{L} / \mathrm{min}$, and (v) a HP8711C network analyzer to follow up phase and modulus variations versus time at a fixed frequency (See Supplementary Materials Figure S4).

Prior to the detection of the anlytes of interest, the SAW devices were cleaned with acetone and ethanol and then with a piranha solution $\left(98 \% \mathrm{H}_{2} \mathrm{SO}_{4} / 30 \% \mathrm{H}_{2} \mathrm{O}_{2} 2: 1 \mathrm{v} / \mathrm{v}\right)$ to remove possible traces of organic contaminants and to activate the gold surfaces [46]. The substrates were after that rinsed with ultra-pure water and ethanol, before being dried under ambient air. A $30 \mu$ l-drop of TDP-AN molecule was then deposited on the SAWs sensing area, by drop-cast, and the SAW device placed into an oven at $60^{\circ} \mathrm{C}$, to evaporate the chloroform solvent.

\section{Results and Discussion}

\subsection{Analytical Modeling Using MATLAB Software}

The interest of MATLAB is to rapidly simulate the mathematical behavior of a SAW device in terms of transfer function. This can be done by considering an elementary equivalent electrical circuit, in which the operating frequency is related to the surface acoustic wave propagation. In this study, we have used the impulse response method which was developed by Hartmann, Bell, and Rosenfeld [47]. The Masson's equivalent circuit is often used to represent the electrical behavior of basic interdigital transducers (IDT). To take fast volume waves into account, we proposed a second identical circuit in parallel as shown in Figure 1.
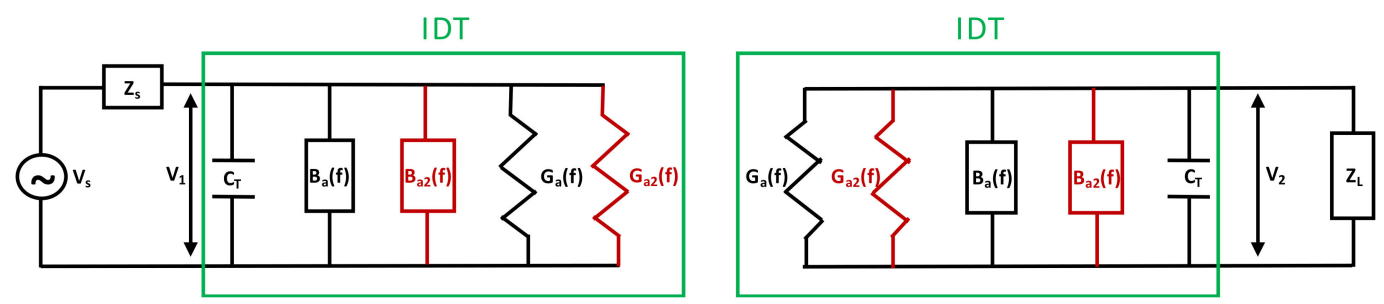

Figure 1. Schematic view of two equivalent circuits which takes into account both surface and volume acoustic waves.

The equivalent circuit of IDT transducer consists of a total capacitance $\left(C_{T}\right)$ and two radiation admittances $Y_{a i}$ for surface and volume acoustic waves (Equation (1)):

$$
Y_{a i}(f)=G_{a i}(f)+j \times B_{a i}(f)(i=1,2)
$$


The real part $G_{a i}(f)$ represents the radiation conductance, while the imaginary one, $B_{a i}(f)$, is the acoustic susceptance determined from the Hilbert transform of the real part [47]. This proposed simple model allows the implementation of the corresponding mathematical equations in MATLAB software to quasi-instantaneously extract the system frequency response. MATLAB code has been successfully written and checked to perform the required analysis. Here, we considered a structure of 30 pairs of double fingers, operating at $104 \mathrm{MHz}$. Input parameters implemented in MATLAB code are gathered in Table 1.

Table 1. Input parameters implemented in MATLAB software to model a $\mathrm{LiTaO}_{3}-104 \mathrm{MHz}$ surface acoustic wave (SAW) device.

\begin{tabular}{cc}
\hline Parameters & Values \\
\hline Electromechanical coupling coefficient $\left(\mathrm{K}^{2}\right)$ & 0.047 \\
Surface wave velocity & 4160 \\
& $\mathrm{~m} \cdot \mathrm{s}^{-1}$ \\
Fast bulk wave velocity & $\approx 5600$ \\
Operating frequency $\left(\mathrm{f}_{0}\right)$ & $\mathrm{m} \cdot \mathrm{s}^{-1}$ \\
Number of finger pairs $\left(\mathrm{N}_{\mathrm{p}}\right)$ & $104 \mathrm{MHz}$ \\
Aperture $\left(\mathrm{W}_{\mathrm{a}}\right)$ & 30 \\
Length of delay line $(\mathrm{D})$ & $2000 \mu \mathrm{m}$ \\
Source and load impedance $\left(\mathrm{Z}_{\mathrm{s}}\right.$ et $\left.\mathrm{Z}_{\mathrm{L}}\right)$ & $8010 \mu \mathrm{m}$ \\
Capacitance per unit length for a pair of fingers $\left(\mathrm{C}_{\mathrm{s}}\right)$ & $50 \Omega$ \\
Total static capacitance $\left(\mathrm{C}_{\mathrm{T}}\right)$ & $6.04 \mathrm{pF} / \mathrm{m}$ \\
\hline
\end{tabular}

To assess the validity of this simplified model, a computation was done on a delay line configuration close to the real SAW device. Results, presented in Figure 2, show a good agreement between calculated and experimental S21 spectra, in terms of insertion loss (-19 dB measured against $-20 \mathrm{~dB}$ calculated) and shape around the operating frequency $\left(\mathrm{f}_{0}=104 \mathrm{MHz}\right)$. However, the bandwidth is slightly wider in the measured S21 spectrum than in the calculated one. This difference is probably due to the real losses in the piezoelectric material as well as to the imperfections in the real geometry of the IDTs (metallization rate, aperture, roughness, etc.), considered as ideal in the calculations.

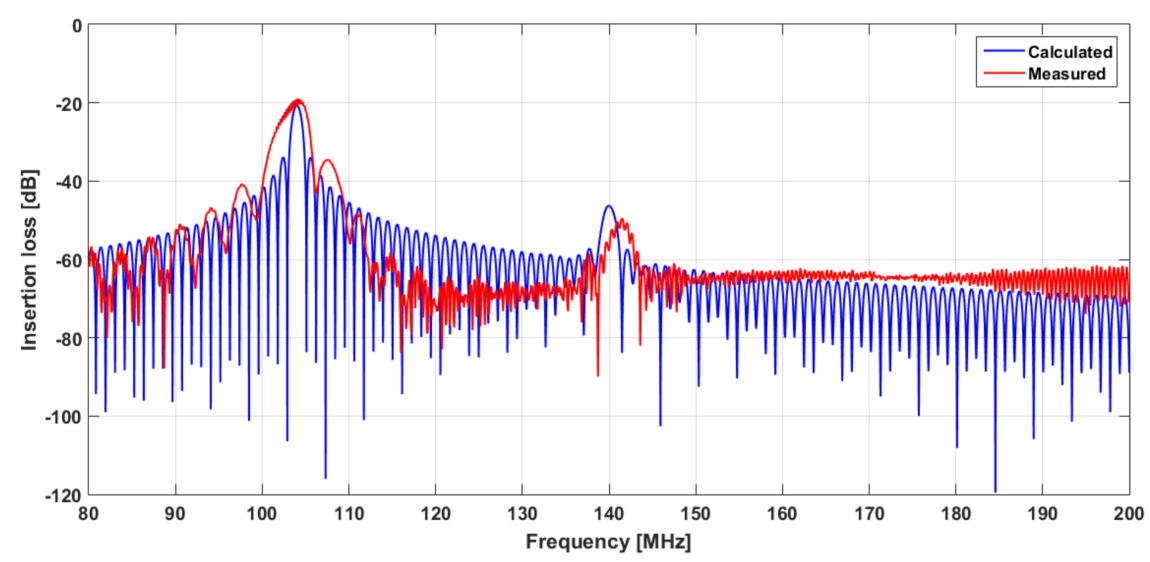

Figure 2. Calculated and measured insertion loss spectra of SAW delay line.

For the value of bulk wave frequency $(\approx 140 \mathrm{MHz})$, calculation can be adjusted to closely fit the experimental value, but at this stage, this is not essential, as our main objective is focused on surface acoustic waves.

From results presented in Figure 2, we clearly showed that MATLAB software can be used as a first approach to simulate the electrical behavior of a SAW delay line device. Nevertheless, this simulation does not consider several other parameters such as reflections between finger pairs, triple transit, 
and reflections at the edges of the substrate. Obviously, each of these parameters can be taken into account in the calculations, but this would make the model very complex. Alternatively, we considered a FEM simulation to overcome these limitations, as this method consider both physical and electrical properties of the piezoelectric substrate.

\subsection{Numerical Simulation with COMSOL Multiphysics}

A COMSOL Multiphysics-based 3D model was created on 36 lithium tantalate $\left(\mathrm{LiTaO}_{3}\right)$ piezoelectric substrate. Input and output IDTs (30 finger pairs each, fingers width $=5 \mu \mathrm{m}$ ) were in $\mathrm{Cr} / \mathrm{Au}(20 \mathrm{~nm} / 80 \mathrm{~nm})$ with a periodicity of $\lambda=40 \mu \mathrm{m}$ (i.e., operating frequency $\mathrm{f}_{0}=104 \mathrm{MHz}$ ), and separated by a sensing area of $80 \mu \mathrm{m}$ length (Figure 3). To save time, we chose to reduce the length of the sensing area instead of using large meshes.
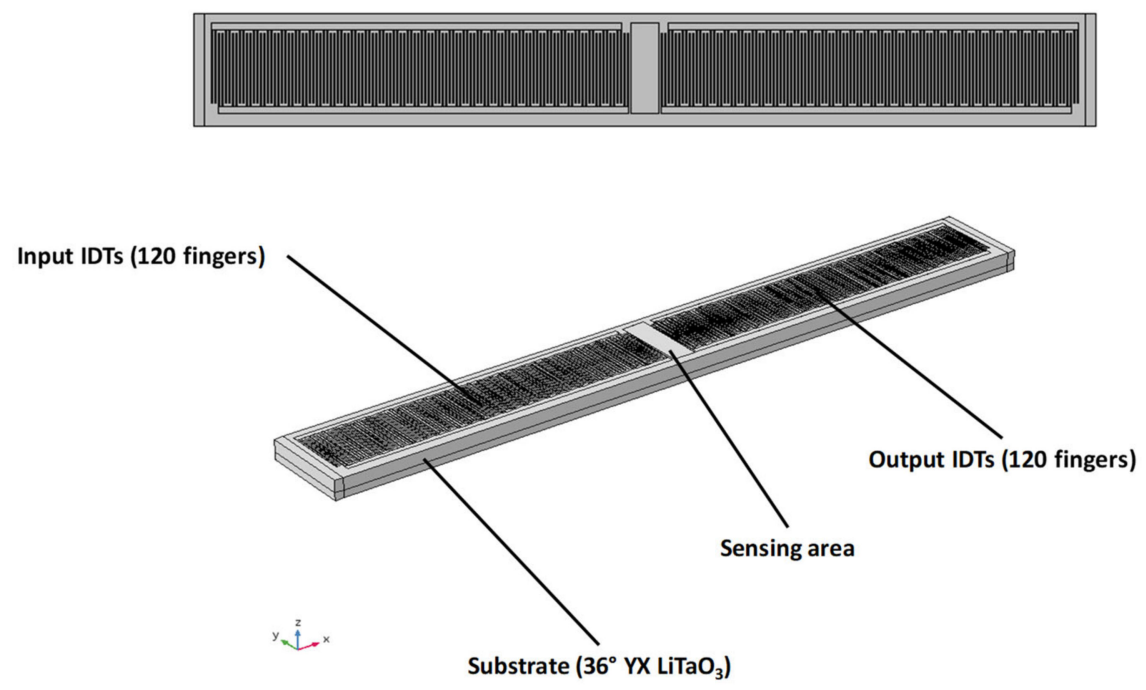

Figure 3. FEM 3D geometry of SAW device.

The simulations were run from $80 \mathrm{MHz}$ to $200 \mathrm{MHz}$ with a frequency step of $100 \mathrm{kHz}$, and the obtained S21 spectrum was compared to the experimental one (Figure 4). Results show a good agreement between computations and measurements, in terms of shape, around the operating frequency $\left(\mathrm{f}_{0} \approx 104 \mathrm{MHz}\right)$, insertion loss values, and bandwidth. We also notice the presence of the expected "peak" around $140 \mathrm{MHz}$, characteristic of fast volume waves.

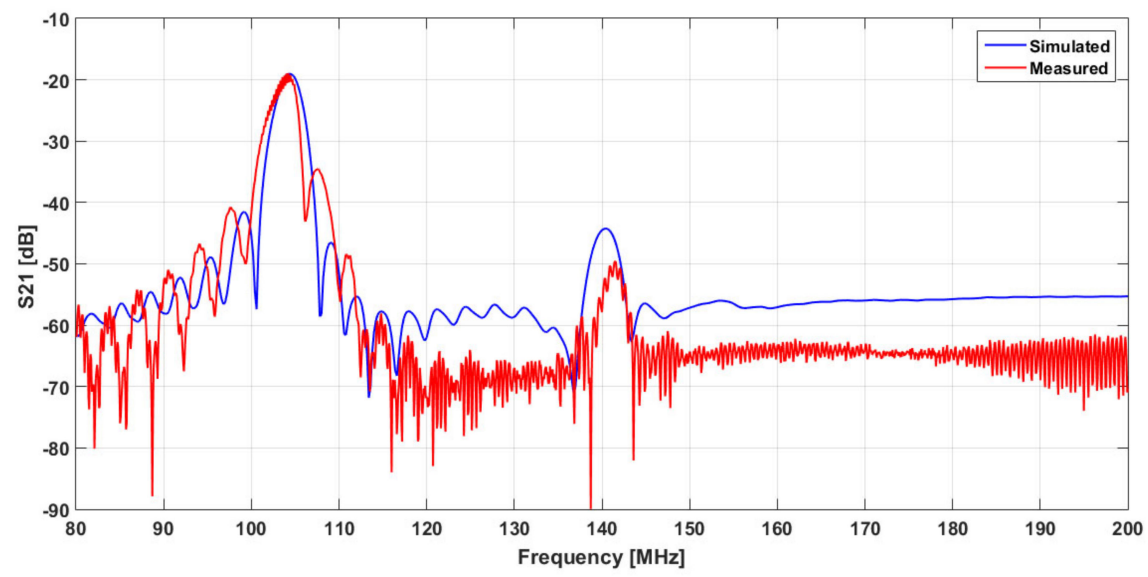

Figure 4. Simulated (3D model COMSOL, configuration: 30 pairs of double fingers + metallized sensing area of $80 \mu \mathrm{m}$ length) and measured S21 spectra of SAW delay line. 
Even though the length of the sensing area has been drastically reduced (two orders of magnitude), this interesting 3D model remains time consuming (six weeks). A 2D model was thus investigated to reduce calculations durations. We first considered simpler structures, with two, then three pairs of double fingers, to assess the similarity between 2D and 3D models results (results not shown here). Once ensured of results concordance, we simulated a 2D structure with 30 pairs of fingers, having an $8 \mathrm{~mm}$ length sensing area, the same as the experimental device. The simulations were run from $80 \mathrm{MHz}$ to $200 \mathrm{MHz}$ with a frequency step of $100 \mathrm{kHz}$ to access S21 parameter. Calculations duration was of the order of $14 \mathrm{~h}$, largely inferior to that needed for a 3D model. The comparison between calculation and experimental spectrum (Figure 5) highlights a good agreement between the two spectra in terms of gain and expected shape around $104 \mathrm{MHz}$. The disappearance of the characteristic frequency around $140 \mathrm{MHz}$, characteristic of bulk waves, can be attributed to the geometrical conditions, as BAWs detection is indirect (from backscattering). However, this is not limiting, as the main objective of this study is related to the investigation of the surface acoustic waves.

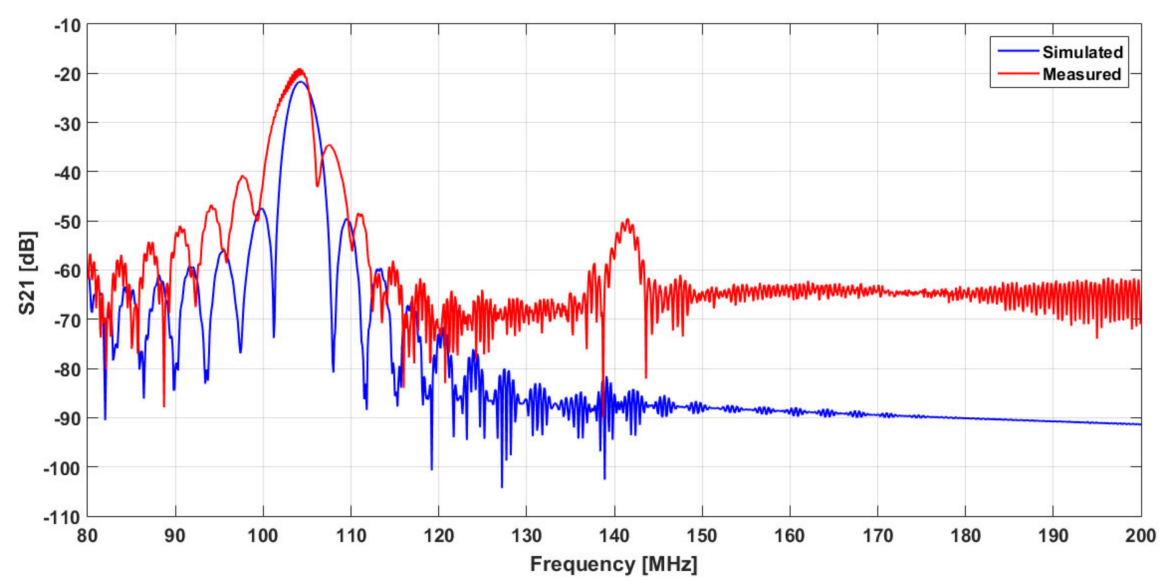

Figure 5. Simulated (2D model COMSOL of configuration: 30 pairs of double fingers + metallized sensitive area of $8 \mathrm{~mm}$ length) and measured S21 spectra of SAW delay line.

Subsequently, and to save calculation time, we reduced the length of the sensing area by one then two orders of magnitude. Results presented in Figure 6 indicate that S21 spectrum corresponding to the extended area $(8 \mathrm{~mm})$, is the closest to the experimental one (regarding surface waves only). It is therefore this configuration that was thus considered for further investigations.

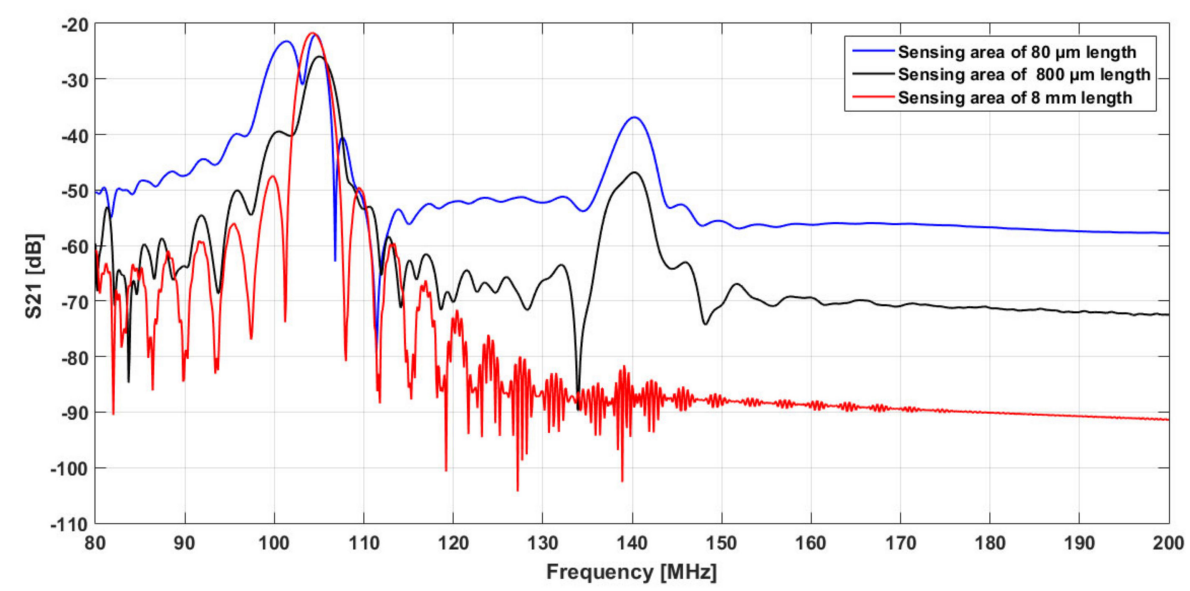

Figure 6. Simulated S21 spectra for different length of sensitive area. 
On the basis of the whole comparison results, we have made the choice of considering 2D simulation to accurately study the response of a $208 \mathrm{MHz}$ SAW device and to check the sensitivity enhancement with frequency.

\subsection{SAW Device Sensitivity Enhancement with Operating Frequency Increase}

To design a $208 \mathrm{MHz}-\mathrm{SAW}-2 \mathrm{D}$ delay line, we have considered the same $\mathrm{LiTaO}_{3}$ piezoelectric substrate. Input and output IDTs (30 finger pairs each, fingers width $=2.5 \mu \mathrm{m}$ ) were designed in $\mathrm{Cr} / \mathrm{Au}(20 \mathrm{~nm} / 80 \mathrm{~nm})$ with a periodicity of $\lambda=20 \mu \mathrm{m}$. A metallized $\mathrm{Cr} / \mathrm{Au}(20 \mathrm{~nm} / 80 \mathrm{~nm})$ sensing area of $8 \mathrm{~mm}$ length separates the input and output IDTs. The simulations were run from $140 \mathrm{MHz}$ to $260 \mathrm{MHz}$ with a frequency step of $100 \mathrm{kHz}$. The corresponding calculated spectrum will be compared to experimental one (after the design of $208 \mathrm{MHz}-\mathrm{SAW}$ ) at the end of this section.

To compare the sensitivities of $104 \mathrm{MHz}$ and $208 \mathrm{MHz}$ chemical sensors, we designed 2D chemical sensors in which a $500 \mathrm{~nm}$ thick layer of polyisobutylene (PIB) was deposited on the entire surface of each delay line. PIB plays the role of a dichloromethane (DCM) recognition layer (Figure 7). Sensitivities were compared in terms of frequency shifts according to DCM concentration.

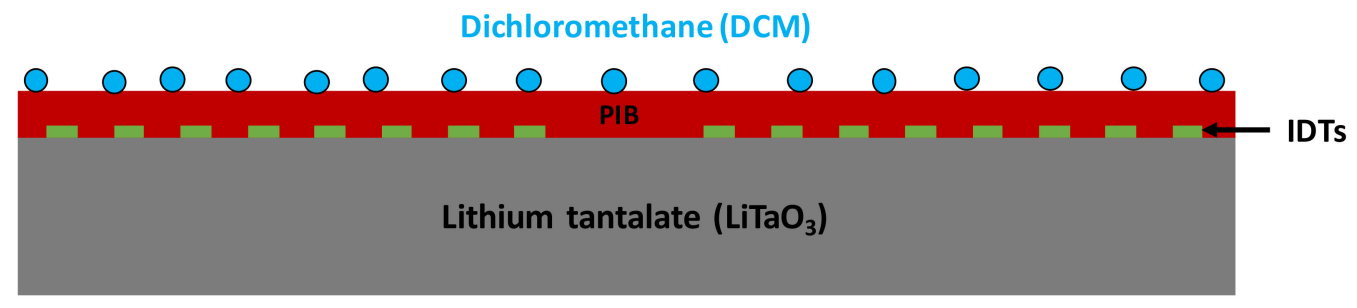

Figure 7. Schematic representation of a SAW device functionalized with a PCB layer for DCM recognition.

Both SAW sensors were exposed to various concentrations of DCM gas ranging from 10 to $1000 \mathrm{ppm}$ at atmospheric pressure and room temperature. DCM adsorption on the PIB layer leads to an increase of the sensing film density, and thus to a decrease of the characteristic frequency, as it is proportional to the adsorbed DCM concentration. The sensitivities of the sensors, estimated from the 2D calculated calibration curves, were of order of $38 \mathrm{mHz} / \mathrm{ppm}$ and $152 \mathrm{mHz} / \mathrm{ppm}$ for $104 \mathrm{MHz}$ and $208 \mathrm{MHz}$ sensors, respectively (Figure 8). Notice that only DCM molecules, "adsorbed on" PIB, were considered in this approach. The enhancement of sensitivity by a factor of four, in line with theory, is encouraging enough to allow consideration of the design and construction of $208 \mathrm{MHz}$ sensors.

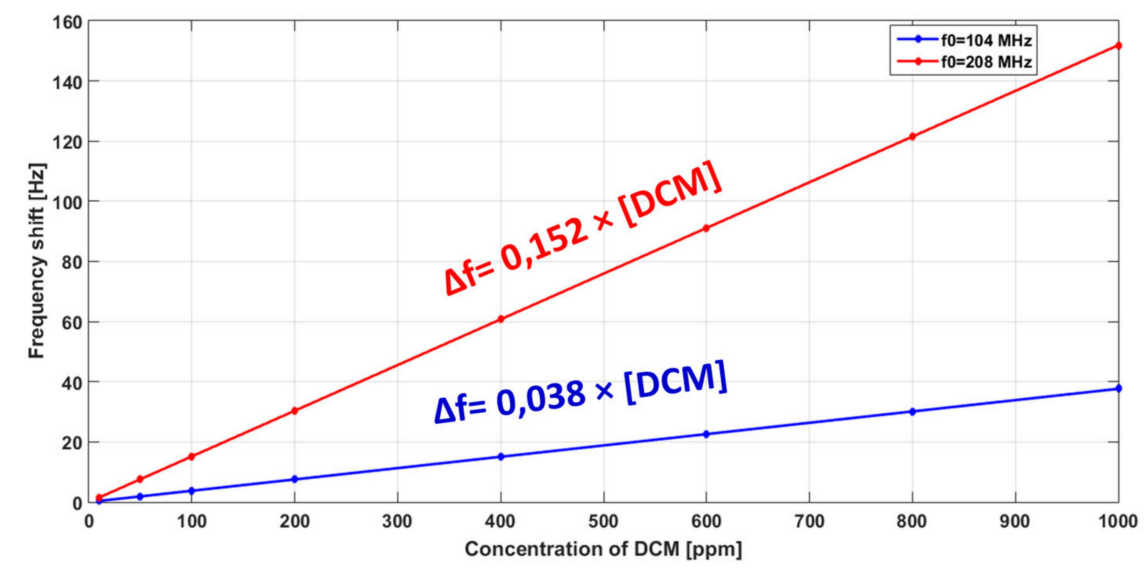

Figure 8. Sensitivity curves for 104 and $208 \mathrm{MHz}$ SAW gas sensors. 
Based on these computational results, a $208 \mathrm{MHz}$ SAW device was realized. Comparison between simulated and experimental spectra is presented in Figure 9. Results show a good agreement between measurements and simulations, in terms of expected shape around the operating frequency, $\left(\mathrm{f}_{0} \approx 208 \mathrm{MHz}\right.$ ). The ultimate goal of the previous part was to show that a 2D COMSOL Mutiphysics configuration permits to obtain all relevant parameters with very substantial time saving. Only the gas medium modeling was therefore done. The main application of SH-SAW sensors remains however the detection of analytes in liquid media. In this study, we made the choice to design 104 and $208 \mathrm{MHz}$ devices for the detection of zinc ions in aqueous solutions.

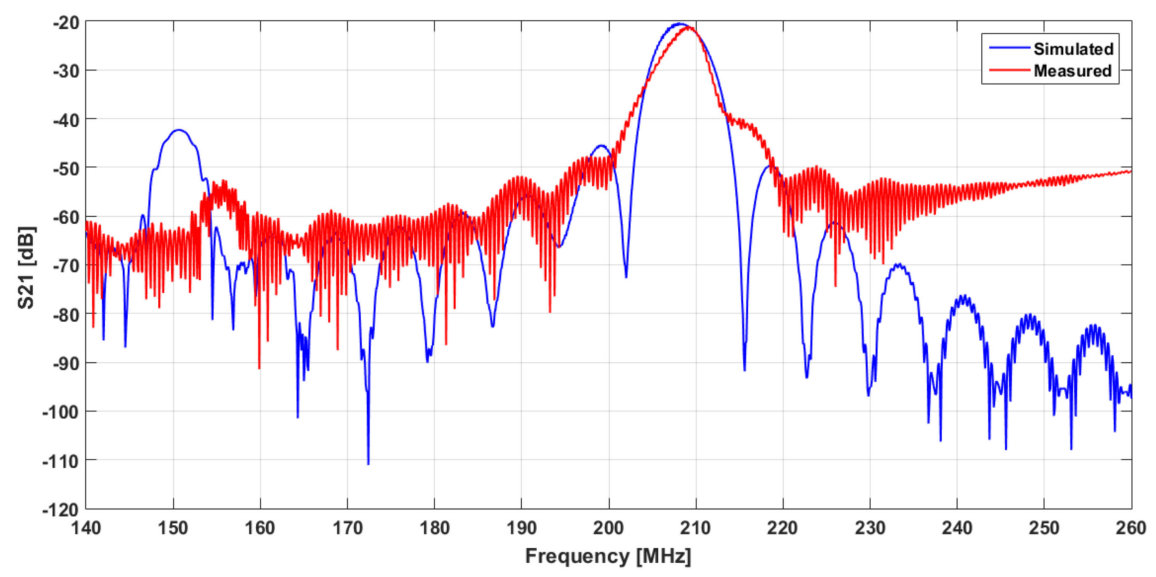

Figure 9. Simulated (2D model COMSOL, configuration: 30 pairs of double fingers + metallized sensitive area of $8 \mathrm{~mm}$ length) and measured S21 spectra of SAW delay line.

\subsection{Design of TDP-AN SAW Sensors}

\subsubsection{Functionalization Step}

The key step for the design of a chemical or biological sensor is the success of the sensing area functionalization step. Here, we have recorded the S21 spectra before and after TDP-AN drop cast on the sensing area of both 104 and $208 \mathrm{MHz}$ SAW sensors (Figure 10).
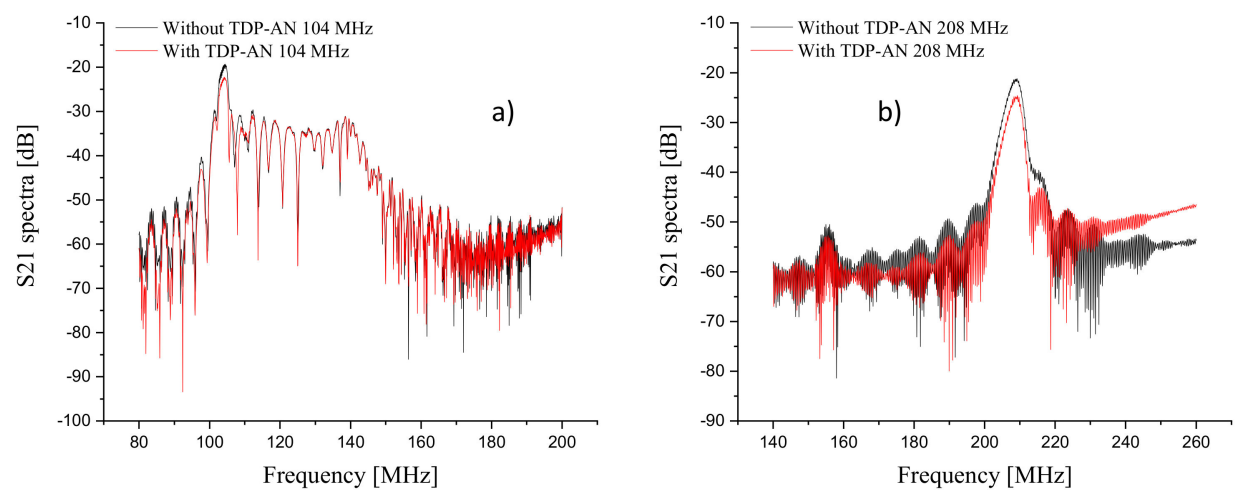

Figure 10. S21 spectra before and after the sensing area functionalization with TDP-AN molecule (a) for $104 \mathrm{MHz}$ SAW; (b) for $208 \mathrm{MHz}$ SAW.

The functionalization causes a decrease of order of $3.5 \mathrm{~dB}$ and $3.9 \mathrm{~dB}$ of the transfer function modulus for 104 and $208 \mathrm{MHz}$ sensors, respectively, confirming the successful adhesion of TDP-AN on the sensing areas. 


\subsection{2. $\mathrm{Zn}^{2+}$ Detection}

The monitoring of zinc ions detection was investigated by following up the temporal variation of phase shift, for a fixed operating frequency. Prior to ions injection, a constant flow of double ionized (DI) water was brought, at a constant rate of $190 \mu \mathrm{L} / \mathrm{min}$, on the sensing area of each SAW sensor. Once the stabilization reached, $10 \mu \mathrm{L}$ of zinc ions solution of given concentration was injected into the fluidic circuit. This leads to a decrease of the phase output signal, indicating that TDP-AN molecule recognizes the analyte. Here, we have chosen to present the phase shift variations as a function of time after the injection of $10^{-6} \mathrm{M}$ and $10^{-3} \mathrm{M}$ of zinc ions for $104 \mathrm{MHz}$ SAW sensor. The typical gravimetric responses are reported on Figure 11.
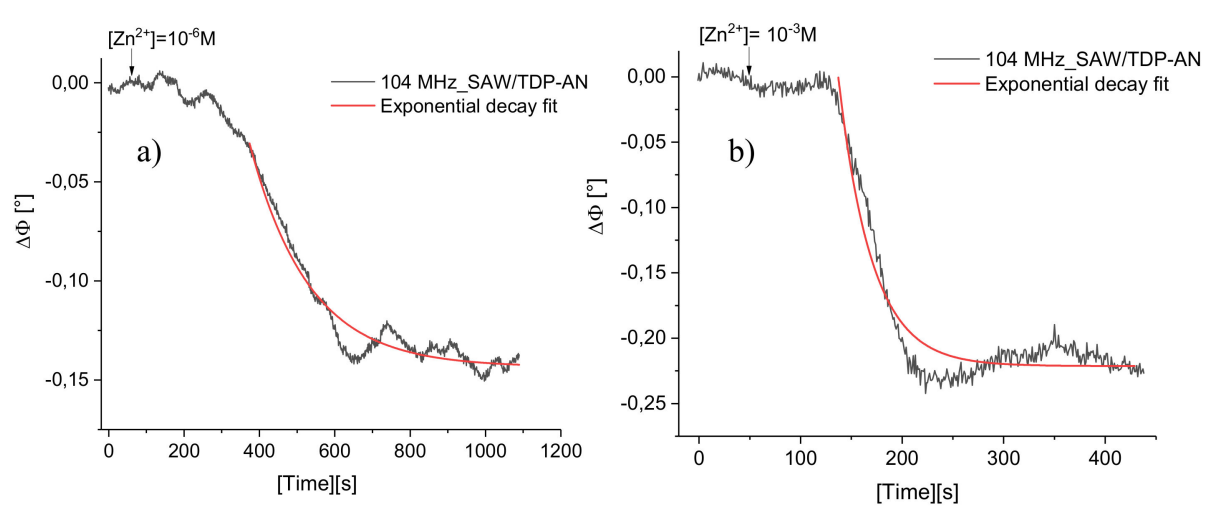

Figure 11. Phase-shift $(\Delta \Phi)$ variations versus time for $104 \mathrm{MHz}$ _SAW/TDP-AN sensor after the injection of a zinc ion solution at a concentration of (a) $10^{-6} \mathrm{M}$; (b) $10^{-3} \mathrm{M}$.

To provide information on the kinetic of interaction between TDP-AN and $\mathrm{Zn}^{2+}$ ions, Figure 11a,b were fitted with an exponential decay function. The corresponding time constants were of order of

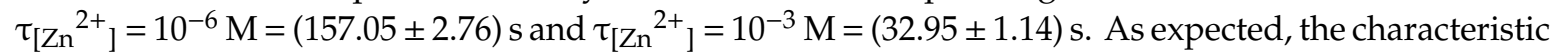
time constant following the $\mathrm{Zn}^{2+}$ ions injection at a concentration of $10^{-6} \mathrm{M}$ is higher than that obtained after adding of $10^{-3} \mathrm{M}$ of zinc ion solution. Difference of the $\tau$ values after the two considered concentrations was also observed in the case of $208 \mathrm{MHz} \_$SAW/TDP-AN sensor (Figures are not shown here).

Phase-shift variations $(\Delta \Phi)$ versus cumulative $\mathrm{Zn}^{2+}$ concentration for 104 and $208 \mathrm{MHz}$ sensors are plotted in Figure 12. Each calibration curve was obtained by averaging three successive experiments. Results were compared in terms of limit of detection (LOD), dissociation constant $\mathrm{K}_{\mathrm{d}}$, and sensitivity.

Limit of detection (LOD) is usually calculated from the signal to noise ratio. Here, we defined it as the lowest concentration detected by each functionalized SAW sensor. Gravimetric results indicate that the LOD was of about $0.1 \mathrm{nM}$ for both sensors. Results, presented in Figure 12a, also indicate that the phase shift value at saturation $\Delta \Phi \mathrm{s}(208 \mathrm{MHz})$ is slightly superior to that of $\Delta \Phi \mathrm{s}(104 \mathrm{MHz})$, showing that increasing of operating frequency, from $104 \mathrm{MHz}$ to $208 \mathrm{MHz}$, permitted to increase the output signal.

Dissociation constant $\left(\mathrm{K}_{\mathrm{d}}\right)$ is among the most important parameters in chemical sensing, as it provides an idea about the degree of affinity between a recognition layer and the further analyte. Here, we have chosen to fit the calibration curves with a Hill model in order to estimate the $K_{d}$ value:

$$
\Delta \Phi(\mathrm{C})=\frac{\mathrm{A} \times \mathrm{C}^{\alpha}}{\mathrm{K}_{\mathrm{d}}^{\alpha}+\mathrm{C}^{\alpha}}
$$

$\Delta \Phi(C)$ corresponds to the phase-shift variations for a given $\mathrm{Zn}^{2+}$ concentration $(\mathrm{C}) ; \mathrm{K}_{\mathrm{d}}$ is the dissociation constant; $\mathrm{A}$ is an empiric constant, which is equal to $\Delta \Phi_{\max }$, i.e., at saturation; and $\alpha$ is the Hill coefficient. 


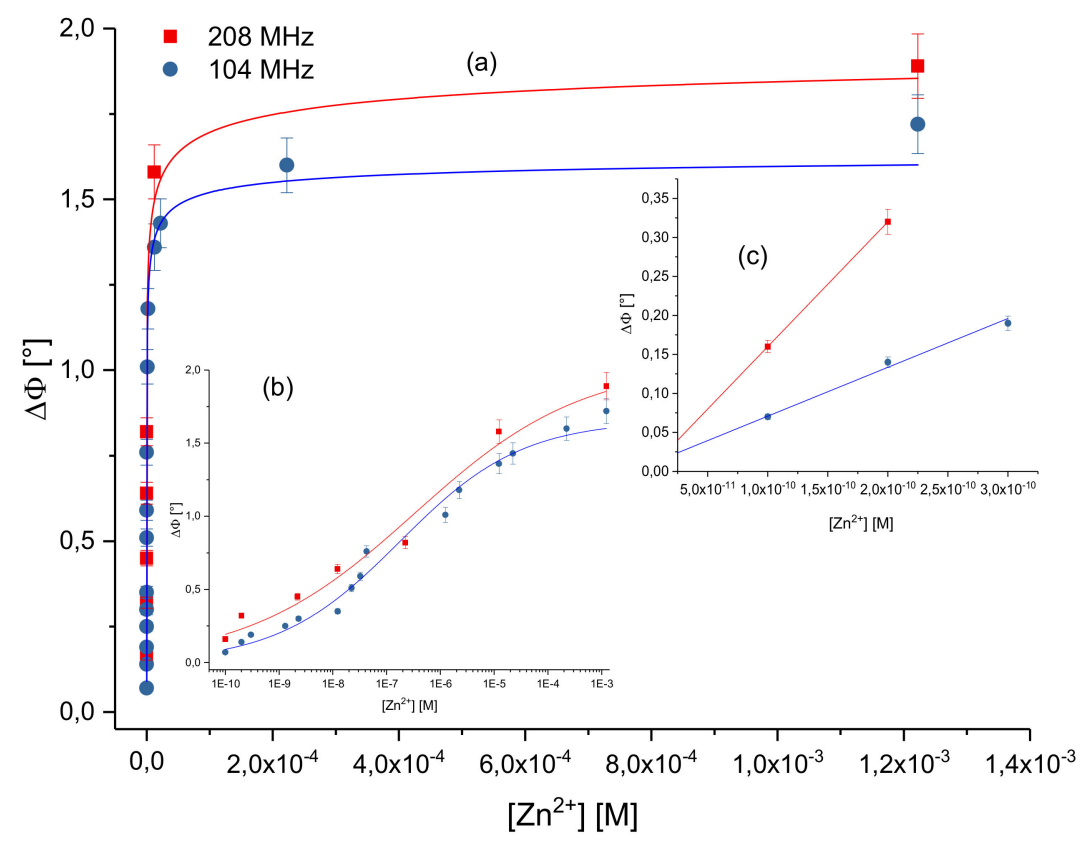

Figure 12. Phase-shift variations $(\Delta \Phi)$ versus cumulative $\mathrm{Zn}^{2+}$ concentration for 104 and $208 \mathrm{MHz}$ SAW sensors functionalized with TDP-AN molecules (a) in linear scale; (b) in logarithmic scale; the red and blue lines correspond to the best fit of experimental data according to the Hill model. (c) Slope at the origin of phase/concentration curves for both 104 and $208 \mathrm{MHz}$ SAW sensors.

Dissociation constants were estimated at: $(2.8 \pm 1.0) \times 10^{-7} \mathrm{M}$ and $(3.4 \pm 2.7) \times 10^{-7} \mathrm{M}$ for 104 and $208 \mathrm{MHz}$, respectively. These results exhibit comparable values for $\mathrm{K}_{\mathrm{d}}$, within uncertainties, showing no effect of frequency as expected. Indeed, $K_{d}$ constant is related to the interaction between TDP-AN molecule and $\mathrm{Zn}^{2+}$ ions and is therefore independent of the sensing method. Hill coefficient was of order of $(0.36 \pm 0.042)$ and $(0.27 \pm 0.03)$ for 104 and $208 \mathrm{MHz}$ sensors, respectively, indicating negative cooperative interactions between TDP-AN and the binding sites [48].

Because of the non-linearity of the response of both sensors, their sensitivities were estimated from the slope at the origin of their respective calibration curves (Figure 12c). The obtained values were of the order of $(7.0 \pm 2.8) \times 10^{8}\left[{ }^{\circ} / \mathrm{M}\right]$ and $(16.0 \pm 7.6) \times 10^{8}\left[{ }^{\circ} / \mathrm{M}\right]$ for $104 \mathrm{MHz}$ and $208 \mathrm{MHz}$ sensors, respectively, indicating that the SAW sensitivity increases with frequency. The $\left(\mathrm{S}_{208} \mathrm{MHz} / \mathrm{S}_{104} \mathrm{MHz}\right)$ experimental ratio was of order of 2.3, a value which is inferior to the theoretical one (equal to 4) [49]. These unbalanced values (2.3 and 4) indicate that the mass-loading is not the unique element which contributes to a SAW response. However, this increase in sensitivity augurs success for future applications intended to quantify very small quantities of pollutants in water.

\section{Conclusions}

MATLAB software is used as simulation tool to get access to the frequency response (S21 spectrum) of SAW delay line, with reasonable calculation time. By using the impulse response model where we have considered both surface and fast volume waves, instead of the former only as is usually the case, we achieve a good agreement between calculation and experiment. A full characterization, including second order effects (multiple reflections, interferences ... ) ) were then investigated by FEM simulations using COMSOL Multiphysics software. 3D simulations were in line with experiments, highlighting the robustness and accuracy of the considered model. Notwithstanding, and to significantly reduce the computation time, 2D models were built and compared to the 3D one. Results clearly shown that it is possible to accurately obtain all pertinent parameters with $2 \mathrm{D}$ simulations. The latter can thus be used with complete confidence to optimize the desired structures before any realization step. To evaluate the increase in sensitivity with the operating frequency, the $104 \mathrm{MHz}$ and $208 \mathrm{MHz}$ delay 
lines were modified with a polyisobutylene (PIB) to become sensitive to dichloromethane (DCM) gas. Simulations showed that sensitivity value was increased by a factor of four, in accordance with the theory, which encouraged us to develop a $208 \mathrm{MHz}$ delay line in addition to the existing one (104 MHZ SAW sensor). The two realized devices were then tested as chem-sensors to detect zinc ions in solution and compared, mainly in terms of limit of detection (LOD), dissociation constants $\left(\mathrm{K}_{\mathrm{d}}\right)$, and sensitivity. For that, the $104 \mathrm{MHz}$ and $208 \mathrm{MHz}$ SAW sensors were functionalized with an anthracene derivate molecule (TDP-AN) as a sensing layer. As expected, the estimated values of LOD and $\mathrm{K}_{\mathrm{d}}$ were comparable for both sensors. Gravimetric results indicate also that the increasing of operating frequency, from $104 \mathrm{MHz}$ to $208 \mathrm{MHz}$, permitted to enhance the sensitivity by a factor of 2.3.

This work paves the way for the use of the TDP-AN/208 MHz SAW sensor in the Sarthe River Basin to detect heavy metal ions, especially zinc.

Supplementary Materials: The following are available online at http://www.mdpi.com/1424-8220/20/17/4994/s1, Figure S1: Manufacturing process of SAW devices in LAUM's clean room, Figure S2: Photos of the SAW sensor and further details of the interdigital transducers (IDTs), Figure S3: Details of the printed circuit board (PCB), Figure S4: Details of the fluidic system

Author Contributions: Conceptualization and methodology, N.F., C.Z., and N.Y.; software, investigation, and writing-original draft preparation, B.A.; formal analysis and data curation, B.A. and G.A.; validation, N.F. and C.Z.; writing-review and editing, N.F. and C.Z.; visualization, N.F., C.Z., N.Y., and K.R.; supervision, N.F., C.Z., and N.Y.; funding acquisition, N.Y. All authors have read and agreed to the published version of the manuscript.

Funding: This research was funded by "La région Pays de la Loire", WISE/RCSF project.

Acknowledgments: N. Yaakoubi and B. Achour wish to thank "La région Pays de la Loire" for the financial support through the WISE/RCSF project.

Conflicts of Interest: The authors declare no conflict of interest.

\section{References}

1. Campbell, C. Surface Acoustic Wave Devices and Their Signal Processing Applications, 1st ed.; Academic Press: San Diego, CA, USA, 1989.

2. Campbell, C. Surface Acoustic Wave Devices for Mobile and Wireless Communications; Academic Press: San Diego, CA, USA, 1998.

3. Hashimoto, K.-Y. Surface Acoustic Wave Devices in Telecommunications: Modelling and Simulation; Springer: Berlin/Heidelberg, Germany, 2000.

4. Gell, J.R.; Ward, M.B.; Young, R.J.; Stevenson, R.M.; Atkinson, P.; Anderson, D.; Jones, G.A.; Ritchie, D.A.; Shields, A.J. Modulation of single quantum dot energy levels by a surface-acoustic-wave. Appl. Phys. Lett. 2008, 93, 081115. [CrossRef]

5. Aigner, R. SAW and BAW technologies for RF filter applications: A review of the relative strengths and weaknesses. In Proceedings of the 2008 IEEE Ultrasonics Symposium, Beijing, China, 2-5 November 2008; pp. 582-589.

6. Xuan, W.; He, M.; Meng, N.; He, X.; Wang, W.; Chen, J.; Shi, T.; Hasan, T.; Xu, Z.; Xu, Y.; et al. Fast Response and High Sensitivity $\mathrm{ZnO} /$ glass Surface Acoustic Wave Humidity Sensors Using Graphene Oxide Sensing Layer. Sci. Rep. 2014, 4, 7206. [CrossRef]

7. Morales-Rodríguez, M.E.; Joshi, P.C.; Humphries, J.R.; Fuhr, P.L.; Mcintyre, T.J. Fabrication of Low Cost Surface Acoustic Wave Sensors Using Direct Printing by Aerosol Inkjet. IEEE Access 2018, 6, 20907-20915. [CrossRef]

8. Tang, Y.-L.; Li, Z.-J.; Ma, J.-Y.; Su, H.-Q.; Guo, Y.-J.; Wang, L.; Du, B.; Chen, J.-J.; Zhou, W.; Yu, Q.-K.; et al. Highly sensitive room-temperature surface acoustic wave (SAW) ammonia sensors based on $\mathrm{Co}_{3} \mathrm{O}_{4} / \mathrm{SiO}_{2}$ composite films. J. Hazard. Mater. 2014, 280, 127-133. [CrossRef]

9. Tang, Y.; Li, Z.; Ma, J.; Wang, L.; Yang, J.; Du, B.; Yu, Q.; Zu, X. Highly sensitive surface acoustic wave (SAW) humidity sensors based on sol-gel $\mathrm{SiO}_{2}$ films: Investigations on the sensing property and mechanism. Sens. Actuators B Chem. 2015, 215, 283-291. [CrossRef]

10. Eun, K.; Lee, K.J.; Lee, K.K.; Yang, S.S.; Choa, S.-H. Highly sensitive surface acoustic wave strain sensor for the measurement of tire deformation. Int. J. Precis. Eng. Manuf. 2016, 17, 699-707. [CrossRef] 
11. Vanotti, M.; Blondeau-Patissier, V.; Rauch, J.-Y.; Rabus, D.; Mazal, B.; Ballandras, S. SAW sensor exploiting palladium layer properties for selective detection of hydrogen. In Proceedings of the 2013 Joint European Frequency and Time Forum \& International Frequency Control Symposium (EFTF/IFC), IEEE, Prague, Czech Republic, 21-25 July 2013; pp. 775-778.

12. Kabir, K.M.M.; Sabri, Y.M.; Matthews, G.I.; Jones, L.A.; Ippolito, S.J.; Bhargava, S.K. Selective detection of elemental mercury vapor using a surface acoustic wave (SAW) sensor. Analyst 2015, 140, 5508-5517. [CrossRef]

13. Achour, B.; Mazouz, Z.; Fourati, N.; Zerrouki, C.; Aloui, N.; Yaakoubi, N.; Othmane, A.; Kalfat, R. Ultrasensitive Ion Imprinted Polypyrole Polymer Based Piezoelectric Sensors for Selective Detection of Lead Ions. In Proceedings of the 2018 IEEE SENSORS, New Delhi, India, 28-31 October 2018; pp. 1-4.

14. Liu, X.; Wang, W.; Zhang, Y.; Pan, Y.; Liang, Y.; Li, J. Enhanced Sensitivity of a Hydrogen Sulfide Sensor Based on Surface Acoustic Waves at Room Temperature. Sensors 2018, 18, 3796. [CrossRef]

15. Nikolaou, I.; Hallil, H.; Plano, B.; Deligeorgis, G.; Conedera, V.; Garcia, H.; Dejous, C.; Rebière, D. Drop-casted Graphene Oxide Love wave sensor for detection of humidity and VOCs. J. Integr. Circuits Syst. 2016, 11, 49-56.

16. Mensah-Brown, A.K.; Wenzel, M.J.; Josse, F.J.; Yaz, E.E. Near Real-Time Monitoring of Organophosphate Pesticides in the Aqueous-Phase Using SH-SAW Sensors Including Estimation-Based Signal Analysis. IEEE Sens. J. 2009, 9, 1817-1824. [CrossRef]

17. Hashimoto, K.; Yamaguchi, M. Delta function model analysis of SSBW spurious response in SAW devices. In Proceedings of the 1993 IEEE International Frequency Control Symposium, Salt Lake City, UT, USA, 2-4 June 1993; pp. 639-644.

18. Hachigo, A.; Malocha, D.C. SAW dispersive equivalent circuit modeling for diamond layered structures. In Proceedings of the 1996 IEEE Ultrasonics Symposium, San Antonio, TX, USA, USA, 3-6 November 1996; pp. 151-154.

19. Kovacs, G. A generalised P-matrix model for SAW filters. In Proceedings of the 2003 IEEE Symposium on Ultrasonics, Honolulu, HI, USA, 5-8 October 2003; pp. 707-710.

20. Hashimoto, K.; Omori, T.; Yamaguchi, M. Modelling of shear-horizontal-type surface acoustic waves and its application to COM-based device simulation. In Proceedings of the 2001 IEEE Ultrasonics Symposium, Atlanta, GA, USA, 7-10 October 2001; pp. 127-132.

21. Zakaria, M.R.; Hashim, U.; Amin, M.H.I.M.; Ayub, R.M.; Hashim, M.N.; Adam, T. Design and simulation study of high frequency response for surface acoustic wave device by using CST software. AIP Conf. Proc. 2015, 1660, 090043.

22. Achour, B.; Aloui, N.; Fourati, N.; Zerrouki, C.; Yaakoubi, N. Modelling and simulation of SAW delay line sensors with COMSOL Multiphysics. In Proceedings of the MOL2NET 2018, International Conference on Multidisciplinary Sciences, 4th Edition Session BIOCHEMPHYS-01: International Workshop on Med. Chem., Biotech., and Phys. Chem., CNAM, Paris, France, 7 December 2018. [CrossRef]

23. Elhosni, M.; Elmazria, O.; Petit-Watelot, S.; Bouvot, L.; Zhgoon, S.; Talbi, A.; Hehn, M.; Aissa, K.A.; Hage-Ali, S.; Lacour, D.; et al. Magnetic field SAW sensors based on magnetostrictive-piezoelectric layered structures: FEM modeling and experimental validation. Sens. Actuators Phys. 2016, 240, 41-49. [CrossRef]

24. Wang, T.; Green, R.; Guldiken, R.; Wang, J.; Mohapatra, S.; Mohapatra, S.S. Finite Element Analysis for Surface Acoustic Wave Device Characteristic Properties and Sensitivity. Sensors 2019, 19, 1749. [CrossRef] [PubMed]

25. Nikolaou, I.; Hallil, H.; Tamarin, O.; Dejous, C.; Rebiere, D. A three-dimensional model for a graphene guided SH-SAW sensor using finite element method. In Proceedings of the 2016 31st Symposium on Microelectronics Technology and Devices (SBMicro), Belo Horizonte, Brazil, 29 August-3 September 2016; pp. 1-4.

26. Tamarin, O.; Rube, M.; Boissiere, C.; Lachaud, J.L.; Hallil, H.; Dejous, C.; Rebiere, D. Finite Element Modelling design and optimization of Love Wave mesoporous transducers for biochemical detection in liquid medium. In Proceedings of the 2018 3rd International Symposium on Instrumentation Systems, Circuits and Transducers (INSCIT), Bento Goncalves, Brazil, 27-31 August 2018; pp. 1-6.

27. Abdollahi, A.; Jiang, Z.; Arabshahi, S.A. Evaluation on mass sensitivity of SAW sensors for different piezoelectric materials using finite-element analysis. IEEE Trans. Ultrason. Ferroelectr. Freq. Control 2007, 54, 2446-2455. [CrossRef] 
28. Zhao, Y.-G.; Liu, M.; Li, D.-M.; Li, J.-J.; Niu, J.-B. FEM modeling of SAW organic vapor sensors. Sens. Actuators Phys. 2009, 154, 30-34. [CrossRef]

29. Richardson, M.; Sankaranarayanan, S.K.R.S.; Bhethanabotla, V.R. Low Insertion Loss and Highly Sensitive SH-SAW Sensors Based on $36^{\circ} \mathrm{YX} \mathrm{LiTaO}_{3}$ Through the Incorporation of Filled Microcavities. IEEE Sens. J. 2015, 15, 787-796. [CrossRef]

30. Abraham, N.; Reshma Krishnakumar, R.; Unni, C.; Philip, D. Simulation studies on the responses of $\mathrm{ZnO}-\mathrm{CuO} / \mathrm{CNT}$ nanocomposite based SAW sensor to various volatile organic chemicals. J. Sci. Adv. Mater. Devices 2019, 4, 125-131. [CrossRef]

31. Thirumal, V.; Raju, B.; Gandhi, P.; Pandya, H.M. Comparative Modelling Studies of 400 MHz ST-X Quartz SAW Delay Lines for Potential Gas Sensing Applications. Arch. Acoust. 2018, 43, 153-161.

32. Sarthe Department-River Management Office-Water Legislation Dossier-Waterways-29/10/2018. Available online: http://www.sarthe.gouv.fr/IMG/pdf/dossier_loisurleau_entretienvoiesnavigables_vf.pdf (accessed on 30 June 2020).

33. Behnia, N.; Asgari, M.; Feizbakhsh, A. Sub-nanomolar detection of zinc on the ion-imprinted polymer modified glassy carbon electrode. J. Environ. Chem. Eng. 2015, 3, 271-276. [CrossRef]

34. Hande, P.E.; Samui, A.B.; Kulkarni, P.S. Highly selective monitoring of metals by using ion-imprinted polymers. Environ. Sci. Pollut. Res. 2015, 22, 7375-7404. [CrossRef]

35. Kuras, M.J.; Perz, K.; Kołodziejski, W.L. Synthesis, characterization and application of a novel zinc(II) ion-imprinted polymer. Polym. Bull. 2017, 74, 5029-5048. [CrossRef]

36. Xu, J.; Sun, Y.; Sheng, Y.; Fei, Y.; Zhang, J.; Jiang, D. Engineering a DNA-cleaving DNAzyme and PCR into a simple sensor for zinc ion detection. Anal. Bioanal. Chem. 2014, 406, 3025-3029. [CrossRef] [PubMed]

37. Wen, J.T.; Bohorquez, K.; Tsutsui, H. Polydiacetylene-coated polyvinylidene fluoride strip aptasensor for colorimetric detection of zinc(II). Sens. Actuators B Chem. 2016, 232, 313-317. [CrossRef] [PubMed]

38. Rigo, A.A.; Cezaro, A.M.D.; Muenchen, D.K.; Martinazzo, J.; Manzoli, A.; Steffens, J.; Steffens, C. Heavy metals detection in river water with cantilever nanobiosensor. J. Environ. Sci. Health Part B 2020, 55, 239-249. [CrossRef] [PubMed]

39. Xu, H.; Wang, H.; Zhou, S.; Xiao, L.; Yan, Y.; Yuan, Q. A protocol of self-assembled monolayers of fluorescent block molecules for trace Zn(II) sensing: Structures and mechanisms. RSC Adv. 2015, 5, 106061-106067. [CrossRef]

40. Rigo, A.A.; de Cezaro, A.M.; Muenchen, D.K.; Martinazzo, J.; Brezolin, A.N.; Hoehne, L.; Steffens, J.; Steffens, C. Cantilever nanobiosensor based on the enzyme urease for detection of heavy metals. Braz. J. Chem. Eng. 2019, 36, 1429-1437.

41. Turdean, G.L. Design and Development of Biosensors for the Detection of Heavy Metal Toxicity. Int. J. Electrochem. 2011, 2011, 343125. [CrossRef]

42. Eddaif, L.; Shaban, A.; Telegdi, J. Sensitive detection of heavy metals ions based on the calixarene derivatives-modified piezoelectric resonators: A review. Int. J. Environ. Anal. Chem. 2019, 99, 824-853. [CrossRef]

43. Zhang, H.; Faye, D.; Zhang, H.; Lefevre, J.-P.; Delaire, J.A.; Leray, I. Selective detection of heavy metal ions by calixarene-based fluorescent molecular sensors. In Proceedings of the SPIE, Advanced Environmental, Chemical, and Biological Sensing Technologies IX, Baltimore, MD, USA, 23-27 April 2012; Volume 8366, p. 83660I.

44. Nikolelis, D.P.; Raftopoulou, G.; Psaroudakis, N.; Nikoleli, G.-P. Development of an electrochemical chemosensor for the rapid detection of zinc based on air stable lipid films with incorporated calix4arene phosphoryl receptor. Int. J. Environ. Anal. Chem. 2009, 89, 211-222. [CrossRef]

45. Yang, R.; Li, K.; Wang, K.; Zhao, F.; Li, N.; Liu, F. Porphyrin Assembly on $\beta$-Cyclodextrin for Selective Sensing and Detection of a Zinc Ion Based on the Dual Emission Fluorescence Ratio. Anal. Chem. 2003, 75, 612-621. [CrossRef]

46. Mazouz, Z.; Rahali, S.; Fourati, N.; Zerrouki, C.; Aloui, N.; Seydou, M.; Yaakoubi, N.; Chehimi, M.; Othmane, A.; Kalfat, R. Highly Selective Polypyrrole MIP-Based Gravimetric and Electrochemical Sensors for Picomolar Detection of Glyphosate. Sensors 2017, 17, 2586. [CrossRef] [PubMed]

47. Hartmann, C.S.; Bell, D.T.; Rosenfeld, R.C. Impulse Model Design of Acoustic Surface-Wave Filters. IEEE Trans. Microw. Theory Tech. 1973, 21, 162-175. [CrossRef] 
48. Kurganov, B.I.; Lobanov, A.V.; Borisov, I.A.; Reshetilov, A.N. Criterion for Hill equation validity for description of biosensor calibration curves. Anal. Chim. Acta 2001, 427, 11-19. [CrossRef]

49. Penza, M.; Rossi, R.; Alvisi, M.; Aversa, P.; Cassano, G.; Suriano, D.; Benetti, M.; Cannata, D.; Di Pietrantonio, F.; Verona, E. SAW Gas Sensors with Carbon Nanotubes Films. In Proceedings of the 2008 IEEE Ultrasonics Symposium, Beijing, China, 2-5 November 2008; pp. 1850-1853.

(C) 2020 by the authors. Licensee MDPI, Basel, Switzerland. This article is an open access article distributed under the terms and conditions of the Creative Commons Attribution (CC BY) license (http://creativecommons.org/licenses/by/4.0/). 